\title{
17 $\beta$-Estradiol Potentiates the Reinstatement of Cocaine Seeking in Female Rats: Role of the Prelimbic Prefrontal Cortex and Cannabinoid Type-I Receptors
}

\author{
Elizabeth M Doncheck', Luke A Urbanik', Margot C DeBaker', Laura M Barron', Gage T Liddiard', \\ Jennifer J Tuscher', Karyn M Frick ${ }^{2}$, Cecilia J Hillard ${ }^{3}$ and John R Mantsch ${ }^{*, 1}$ \\ 'Department of Biomedical Sciences, Marquette University, Milwaukee, WI, USA; ${ }^{2}$ Department of Psychology, University of Wisconsin-Milwaukee, \\ Milwaukee, WI, USA; ${ }^{3}$ Department of Pharmacology and Toxicology and Neuroscience Research Center, Medical College of Wisconsin, Milwaukee, \\ WI, USA
}

\begin{abstract}
Clinical observations imply that female cocaine addicts experience enhanced relapse vulnerability compared with males, an effect tied to elevated estrogen phases of the ovarian hormone cycle. Although estrogens can enhance drug-seeking behavior, they do not directly induce reinstatement on their own. To model this phenomenon, we tested whether an estrogen could augment drug-seeking behavior in response to an ordinarily subthreshold reinstatement trigger. Following cocaine self-administration and extinction, female rats were ovariectomized to isolate estrogen effects on reinstatement. Although neither peak proestrus levels of the primary estrogen $17 \beta$-estradiol (E2; $10 \mu g / k g$, i.p., I-h pretreatment) nor a subthreshold cocaine dose $(1.25 \mathrm{mg} / \mathrm{kg}$, i.p.) alone were sufficient to reinstate drug-seeking behavior, pretreatment with E2 potentiated reinstatement to the ordinarily subthreshold cocaine dose. Furthermore, E2 microinfusions revealed that E2 $(5 \mu \mathrm{g} / 0.3 \mu \mathrm{l}$, I5-min pretreatment) acts directly within the prelimbic prefrontal cortex (PrL-PFC) to potentiate reinstatement. As E2 has been implicated in endocannabinoid mobilization, which can disinhibit PrL-PFC projection neurons, we investigated whether cannabinoid type-I receptor (CBIR) activation is necessary for E2 to potentiate reinstatement. The CBIR antagonist AM25 I ( or $3 \mathrm{mg} / \mathrm{kg}$, i.p., 30-min pretreatment) administered prior to E2 and cocaine suppressed reinstatement in a dose-dependent manner. Finally, PrL-PFC AM25I microinfusions (300 ng/side, 15-min pretreatment) also suppressed E2-potentiated reinstatement. Together, these results suggest that E2 can augment reactivity to an ordinarily subthreshold relapse trigger in a PrL-PFC CBIR activationdependent manner.

Neuropsychopharmacology (20I8) 43, 78I-790; doi:I0.1038/npp.2017.170; published online 20 September 2017
\end{abstract}

\section{INTRODUCTION}

Correlational clinical studies suggest that cocaine-dependent females experience greater relapse vulnerability than males. Females experience greater difficulty abstaining (Gallop et al, 2007), relapse incidence (Ong et al, 2005), and periods of resumed use following relapse (Carpenter et al, 2006). This heightened vulnerability is therefore a crucial, yet currently untreated, women's health issue. Although women may be more vulnerable to relapse, the neurobiological basis for this sex difference is poorly characterized.

A primary contributor to sex differences in relapse is the ovarian hormone cycle. Elevated estrogens left unopposed by progesterone correspond to increased drug cue-elicited craving (Sinha et al, 2007; Anker and Carroll, 2011),

\footnotetext{
*Correspondence: Dr JR Mantsch, Department of Biomedical Sciences, Marquette University, 56 I N. I5th Street, Schroeder Complex 446, Milwaukee, WI 53233, USA, Tel: +I 414288 2036, Fax: +| 4 I4 288 6564, E-mail: john.mantsch@marquette.edu

Received 6 May 2017; revised 20 July 2017; accepted 4 August 2017; accepted article preview online 21 August 2017
}

impulsive reward-seeking (Reimers et al, 2014), and positive subjective effects of cocaine (Evans and Foltin, 2006; Terner and de Wit, 2006). Preclinical studies using the selfadministration/reinstatement procedure demonstrate higher levels of reinstatement during proestrus, when $17 \beta$-estradiol (E2) levels peak in the rodent estrous cycle (Feltenstein et al, 2011), and estrus, when E2 levels are moderate while progesterone remains low (Kippin et al, 2005; Feltenstein and See, 2007). Reinstatement is, furthermore, facilitated by chronically elevated E2 (Larson et al, 2005). In clinical studies, the higher estrogens and basal progesterone of the follicular phase correspond to greater psychostimulant responsiveness relative to the luteal phase (Terner and de Wit, 2006), and E2 administration during the follicular phase augments the euphoric effects of psychostimulants (Justice and de Wit, 2000). Though these data suggest that elevated estrogens promote the enhanced relapse vulnerability exhibited by females, the mechanisms whereby these effects are produced, and in which brain regions, are not well understood. 
One brain region implicated in relapse is the prelimbic prefrontal cortex (PrL-PFC). A glutamatergic projection from the PrL-PFC to the nucleus accumbens represents a key pathway through which stimuli trigger relapse to cocaine use (Kalivas and Volkow, 2005). Cocaine administration directly into the PrL-PFC is sufficient to trigger reinstatement (Park et al, 2002), while inhibition of the PrL-PFC using tetrodotoxin (Capriles et al, 2003), baclofen/muscimol (McFarland et al, 2003), or optogenetic-based manipulations (Stefanik et al, 2013) prevents cocaine-primed reinstatement. Notably, enhanced cocaine seeking in females corresponds to heightened PrL c-fos reactivity (Zhou et al, 2014), an effect likewise elicited by elevated E2 (Wang et al, 2004). Thus the PrL-PFC represents a likely site for estrogens to promote cocaine seeking.

Endocannabinoids are important regulators of PrL-PFC neuronal excitability (Hill et al, 2011; Martin-Garcia et al, 2016). We have previously reported that glucocorticoids attenuate inhibitory constraint on PrL-PFC pyramidal neurons via mobilization of the endocannabinoid 2arachidonoylglycerol and activation of cannabinoid type-1 receptors (CB1Rs) that regulate GABAergic interneurons (Hill et al, 2011). As E2 has also been reported to mobilize endocannabinoids (Huang and Woolley, 2012; Tabatadze et al, 2015, Peterson et al, 2016), endocannabinoid signaling via PrL-PFC CB1Rs represents a potential mechanism by which estrogens influence cocaine-seeking behavior.

We hypothesized that, in females, estrogens augment reactivity to triggers for cocaine use, thereby conferring enhanced relapse vulnerability. To test this hypothesis, we used a variation of the preclinical self-administration/ reinstatement procedure, which has predictive validity for relapse in humans (Epstein et al, 2006), wherein proestruslevel E2 potentiates reinstatement of drug seeking to an ordinarily subthreshold dose of cocaine. To investigate the role of the PrL-PFC in E2 effects on cocaine seeking, we tested the sufficiency of intra-PrL E2 injections for potentiating cocaine-primed reinstatement. Moreover, to determine the involvement of endocannabinoid signaling, we tested the effect of CB1R antagonism, systemically and intra-PrL-PFC, on E2-potentiated cocaine seeking.

\section{MATERIALS AND METHODS}

\section{Subjects}

Sexually mature female Sprague Dawley rats (90-day old/ $250 \mathrm{~g}$ minimum at study onset) obtained from Envigo (Indianapolis) were single-housed under a reversed 12:12 light-dark cycle (lights off at 0700 hours) with ad libitum access to standard rat chow and water. Experiments were performed in the dark phase and in accordance with the National Institutes of Health Guide for the Care and Use of Laboratory Animals, Eighth edition. All experiments were approved by the Marquette University Institutional Animal Care and Use Committee.

\section{Catheterization and Cannulation}

Rats were surgically implanted with intracranial cannulae and indwelling intravenous catheters for cocaine selfadministration as previously described (Graf et al, 2013;
McReynolds et al, 2016), with minor adaptations. See Supplementary Methods for more information.

\section{Cocaine Self-Administration, Extinction, and Reinstatement Testing}

All self-administration experimental procedures were conducted as previously described (Graf et al, 2013; McReynolds et al, 2016), with minor adaptations. Briefly, females underwent daily 2 -h cocaine self-administration sessions for 10-14 days, followed by extinction training under identical conditions. Following establishment of extinction criterion, all females were surgically OVXed prior to reinstatement except for one cohort tested across the ovarian hormone cycle. Extinction criterion was re-established between tests, which were administered in a counterbalanced design. See Supplementary Methods for more information.

\section{Ovariectomy (OVX)}

Bilateral surgical OVXs were conducted using a dorsal approach as previously described (Twining et al, 2013). See Supplementary Methods for more information.

\section{Drugs}

Cocaine hydrochloride was obtained through the National Institute on Drug Abuse Drug Supply Program. 2-Hydroxypropyl- $\beta$-cyclodextrin (HBC), HBC-encapsulated E2, and AM251 were purchased from Sigma-Aldrich. Cocaine, E2, and HBC were dissolved in $0.9 \%$ bacteriostatic saline. Systemic AM251 was first dissolved in 100\% ethanol and then in Cremaphor and saline in a $1: 1: 18$ ratio. Intra-PrL AM251 was first dissolved in DMSO and then saline in a $1: 9$ ratio.

\section{Statistics}

Statistical analyses were conducted using the SPSS software and consisted of unpaired $t$-tests or one- or two-way repeated-measures ANOVAs followed by Bonferronicorrected post hoc and paired $t$-test analyses when appropriate. Statistical significance was defined as $P<0.05$ for all analyses.

\section{Estrous-Phase Determination and Recapitulation}

Estrous phase was monitored daily by vaginal lavage, with blood samples simultaneously collected by intravenous catheter (see Supplementary Methods). Blood samples were also collected from OVXed females given E2 (10, 50, or $100 \mu \mathrm{g} / \mathrm{kg}$, i.p.; 1 -h pretreatment) or vehicle. To identify a proestrus-recapitulating dose, plasma E2 levels were compared following ELISA measurement (Cayman Chemicals) conducted per the manufacturer's protocol.

\section{Experiment 1: E2-Potentiated Reinstatement of Cocaine Seeking}

Female rats received intravenous catheters and underwent cocaine self-administration and extinction training. To avoid effects on self-administration and extinction and isolate 
effects on reinstatement, rats did not undergo OVX until after establishing extinction criterion. Following recovery and extinction criterion re-establishment, a counterbalanced design was used to administer the following drug treatments $(n=5): \quad$ E2 $\quad(10 \mu \mathrm{g} / \mathrm{kg}, \quad$ i.p.; $\quad 1-\mathrm{h}$ pretreatment $) / \mathrm{saline}$, $\mathrm{HBC} /$ saline, E2/cocaine $(0.625,1.25$, or $2.5 \mathrm{mg} / \mathrm{kg}$, i.p.), and $\mathrm{HBC} /$ cocaine. Animals were re-extinguished to criterion between tests.

\section{Experiment 2: Intra-PrL E2-Potentiated Reinstatement of Cocaine Seeking}

Female rats were surgically implanted with intravenous catheters and bilateral intra-cranial cannulae targeting the PrL-PFC prior to self-administration and extinction. Following extinction establishment, surgical OVX, and then extinction re-establishment, females were tested for reinstatement under the following four conditions $(n=9)$ : intraPrL E2 (5 $\mu \mathrm{g} /$ side.; 15 -min pretreatment)/saline, intra-PrL $\mathrm{HBC} /$ saline, intra-PrL E2/cocaine $(1.25 \mathrm{mg} / \mathrm{kg}$, i.p.), and intra-PrL HBC/cocaine. Following study completion, cannulae placements were assessed (see Supplementary Methods) and anatomical misses were excluded from the study $(n=2)$.

\section{Experiment 3: CB1R Activation Role in E2-Potentiated Reinstatement}

To investigate CB1R involvement in E2-potentiated reinstatement, females underwent cocaine self-administration, extinction, and OVX prior to reinstatement testing under the following five conditions $(n=7)$ : vehicle/E2 $(10 \mu \mathrm{g} / \mathrm{kg}$, i.p.; 1$\mathrm{h}$ pretreatment)/saline; vehicle/HBC/saline; vehicle/HBC/ cocaine $(1.25 \mathrm{mg} / \mathrm{kg}$, i.p.), vehicle/E2/cocaine, and AM251 (1 or $3 \mathrm{mg} / \mathrm{kg}$, i.p.; 30-min pretreatment)/E2/cocaine.

To determine whether CB1R activation is necessary specifically for E2-potentiation effects, and not just the

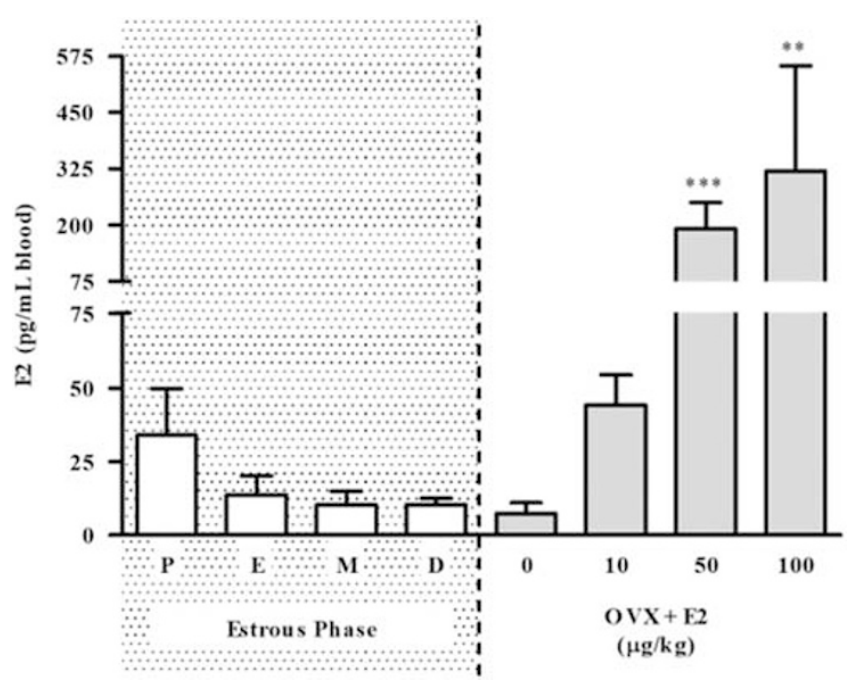

Figure I Proestrus-level E2 recapitulation. Circulating E2 plasma levels corresponding to each estrous phase in gonadally intact females compared with plasma levels evoked by E2 replacement in OVXed females. $\mathrm{P}=$ proestrus, $E=$ estrus, $M=$ metestrus, and $D=$ diestrus. Data are represented as mean $\pm \mathrm{SEM}$. $* * P<0.01$, **** $<<0.00$ I versus proestrus blood levels. priming effects of cocaine, a group of rats was tested for AM251 effects on suprathreshold (eg, $5 \mathrm{mg} / \mathrm{kg}$ ) cocaineprimed reinstatement. Following self-administration, extinction, and OVX, testing occurred under the following conditions $(n=4)$ : vehicle/cocaine $(5 \mathrm{mg} / \mathrm{kg}$, i.p.), AM251 ( 1 or $3 \mathrm{mg} / \mathrm{kg}$, i.p., 30 -min pretreatment)/cocaine.

To determine whether PrL-PFC CB1R activation contributes to E2-potentiated reinstatement, rats underwent catheterization and bilateral intra-PrL cannulation, selfadministration, extinction, and OVX prior to reinstatement testing under the following five conditions $(n=7)$ : intra-PrL vehicle/HBC/saline; intra-PrL vehicle/E2 (10 $\mu$ g/kg, i.p.; 1-h pretreatment)/saline; intra-PrL vehicle/HBC/cocaine $(1.25 \mathrm{mg} / \mathrm{kg}$, i.p.); intra-PrL vehicle/E2/cocaine, and intraPrL AM251 (300 ng/side, 15-min pretreatment)/E2/cocaine. A higher AM251 dose $(1 \mu \mathrm{g} / 0.3 \mu \mathrm{l} / \mathrm{side})$ was also tested, but the increased DMSO concentration (70\%) required to solubilize the drug had non-specific disruptive effects on behavior. Following study completion, cannulae placements were assessed. No anatomical misses were found.

\section{RESULTS}

\section{Estrous-Phase Determination and Recapitulation}

To identify a proestrus-recapitulating dose, E2 blood levels were measured by ELISA across the estrous cycle (proestrus $n=21$, estrus $n=13$, metestrus $n=13$, diestrus $n=11)$. We found peak $\mathrm{pmol} / \mathrm{ml}$ E2 levels $(33.9 \pm 15.8 \mathrm{pg} / \mathrm{ml})$ during proestrus (Figure 1). Next, trunk blood was collected from OVXed females following E2 replacement $(0 \mu \mathrm{g} / \mathrm{kg} n=4$, $10 \mu \mathrm{g} / \mathrm{kg} n=8,50 \mu \mathrm{g} / \mathrm{kg} n=7,100 \mu \mathrm{g} / \mathrm{kg} n=3 ; 1$-h pretreatment). E2 injections dose-dependently increased blood levels (Figure 1), with $10 \mu \mathrm{g} / \mathrm{kg}$ E2 approximating proestrus levels (unpaired $t$-test; $t(27)=0.3853, p=0.7030$ ) and both 50 $(t(26)=3.724, p<0.001)$ and $100 \mu \mathrm{g} / \mathrm{kg} \mathrm{E} 2(\mathrm{t}(22)=3.303$, $p<0.01)$ surpassing physiological levels. We, therefore, conducted testing for E2-potentiated reinstatement using $10 \mu \mathrm{g} / \mathrm{kg}$ E2.

\section{Cocaine Self-Administration and Extinction}

A cocaine self-administration and extinction timeline is depicted in Figure 2a. Responding on the first and last day of self-administration and extinction is summarized for each experiment in Supplementary Table S1 (see Supplementary Materials). Female rats readily acquired cocaine selfadministration and displayed extinction. Neither selfadministration nor extinction varied significantly across experiments.

\section{Experiment 1: E2-Potentiated Reinstatement of Cocaine Seeking in OVXed Females}

We initially tested for reinstatement across a cocaine doseresponse curve to identify a subthreshold dose $(n=5$; Supplementary Figure S1). Similar to previous reports (Lynch and Carroll, 2000), we found 0.625 and $1.25 \mathrm{mg} / \mathrm{kg}$ cocaine to be subthreshold and 2.5 and $5.0 \mathrm{mg} / \mathrm{kg}$ cocaine to be suprathreshold for reinstatement.

To determine the effects of proestrus-level E2 on cocaineinduced reinstatement, we examined the effects of $10 \mu \mathrm{g} / \mathrm{kg}$ 
a

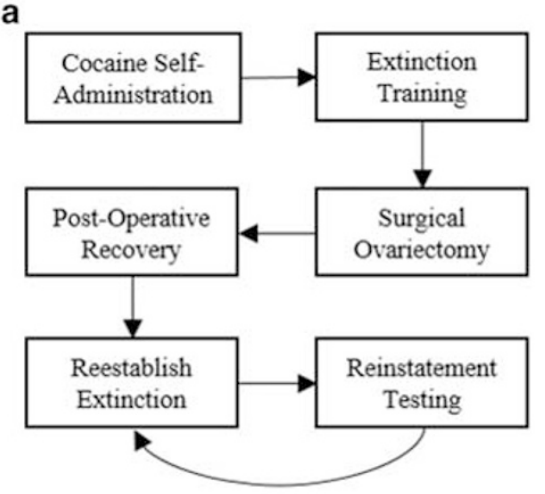

b

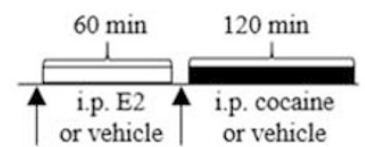

C

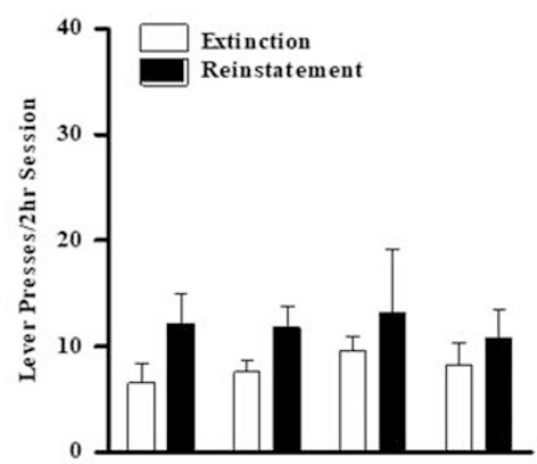

$$
\text { E2 }
$$$$
\begin{aligned}
& 10 \mu \mathrm{g} / \mathrm{kg} \\
& \text { Cocaine }
\end{aligned}
$$

$0.625 \mathrm{mg} / \mathrm{kg}$ d
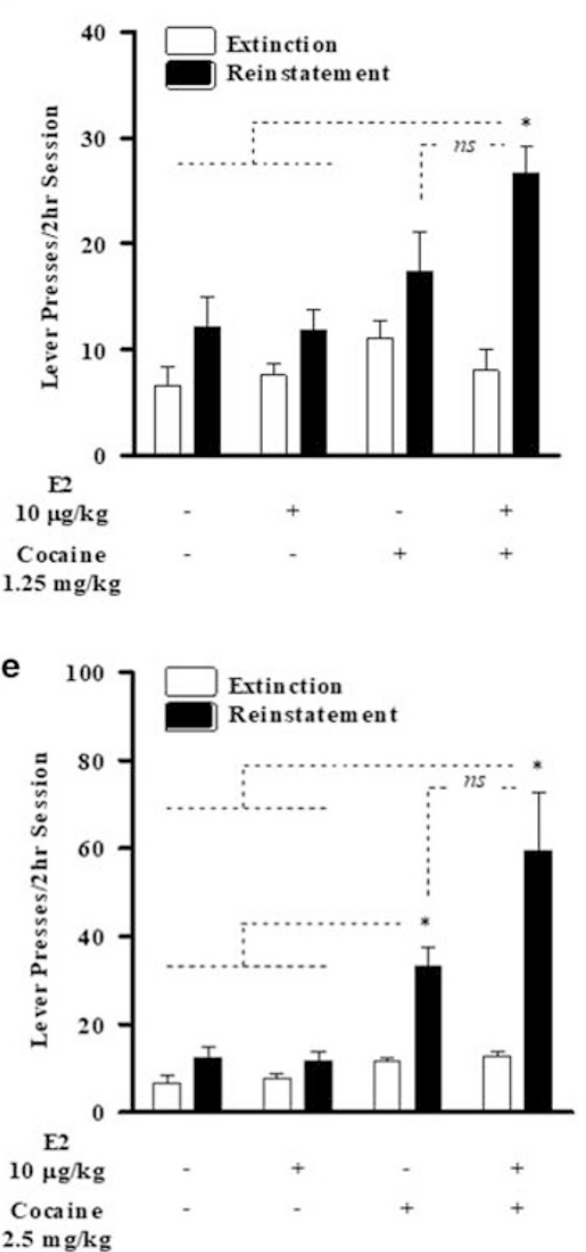

Figure 2 Proestrus-level E2 potentiates the reinstatement of cocaine seeking to subthreshold cocaine priming dose. Following re-establishment of extinction criterion post-ovariectomy, females were tested for reinstatement in response to a $0.625,1.25$, and 2.5 mg/kg cocaine. (a) General timeline for cocaine self-administration and extinction training. (b) Timeline for reinstatement testing. Testing for the effects of I 0 . $\mathrm{gg} / \mathrm{kg}$ E2 on (c) $0.625 \mathrm{mg} / \mathrm{kg}$ cocaine, (d) $1.25 \mathrm{mg} / \mathrm{kg}$ cocaine, and (e) $2.5 \mathrm{mg} / \mathrm{kg}$ cocaine in OVXed females. Data are represented as mean \pm SEM. NS, not significant, $* P<0.05$.

E2 on reinstatement to $0.625 \mathrm{mg} / \mathrm{kg}$ (Figure 2c; $n=5$ ), $1.25 \mathrm{mg} / \mathrm{kg}$ (Figure 2c; $n=5$ ), and $2.5 \mathrm{mg} / \mathrm{kg}$ (Figure $2 \mathrm{~d}$; $n=5)$ priming doses of cocaine; see Figure $2 \mathrm{~b}$ for design. Significant reinstatement was not observed in animals treated with $10 \mu \mathrm{g} / \mathrm{kg}$ E2 alone. Similarly, significant reinstatement was not observed following $0.625 \mathrm{mg} / \mathrm{kg}$ cocaine, either alone or in combination with $10 \mu \mathrm{g} / \mathrm{kg}$ E2 (Figure 2c). However, while $1.25 \mathrm{mg} / \mathrm{kg}$ cocaine alone did not reinstate cocaine seeking, robust reinstatement was observed when this dose was combined with E2 ( $n=5$, Figure $2 \mathrm{~d})$. A two-way repeated-measures ANOVA showed significant main effects of day (extinction $v s$ reinstatement; $\left(\mathrm{F}_{(1,4)}=43.657, \quad p<0.01\right), \quad$ treatment $\quad\left(\mathrm{F}_{(3,12)}=7.015\right.$, $p<0.01)$, and a significant interaction $\left(\mathrm{F}_{(3,12)}=6.286\right.$, $p<0.01)$. Post hoc tests revealed significant reinstatement responding relative to extinction only in the E2/cocaine condition $(p<0.01)$.

To determine whether the E2-potentiated reinstatement observed in OVXed females models reinstatement responding during proestrus, a cohort of gonadally intact females was tested for reinstatement to $1.25 \mathrm{mg} / \mathrm{kg}$ cocaine across the estrous cycle (Supplementary Figure S2). A two-way repeated-measures ANOVA revealed a significant interaction between day (extinction $v s$ reinstatement) and estrous phase $\left(F_{(3,14)}=3.927, p<0.05\right)$, with higher responding during reinstatement relative to extinction in proestrus $(p<0.05)$.

Robust reinstatement was also observed in response to $2.5 \mathrm{mg} / \mathrm{kg}$ cocaine (Figure 2e). A two-way repeated-measures ANOVA revealed significant main effects of day (extinction vs reinstatement, $\left.\mathrm{F}_{(1,4)}=28.297, \quad p<0.01\right)$, treatment $\left(\mathrm{F}_{(3,12)}=12.439, \quad p<0.001\right)$, and a significant interaction $\left(\mathrm{F}_{(3,12)}=7.155, p<0.01\right)$. Post hoc tests revealed significant responding during reinstatement relative to extinction following both $\mathrm{HBC} /$ cocaine $(p<0.01)$ and E2/cocaine $(p<0.05)$. Although not statistically significant, higher reinstatement responding was observed in the E2/cocaine condition compared with $\mathrm{HBC} /$ cocaine.

We also determined the relationship between E2 dose (0, 10, 50, and $100 \mu \mathrm{g} / \mathrm{kg}$, i.p.; 1-h pretreatment) and reinstatement to subthreshold cocaine $(0.625 \mathrm{mg} / \mathrm{kg}$, i.p.; Supplementary Figure S3). A two-way repeated-measures 


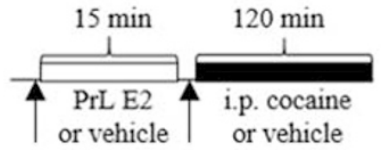

b

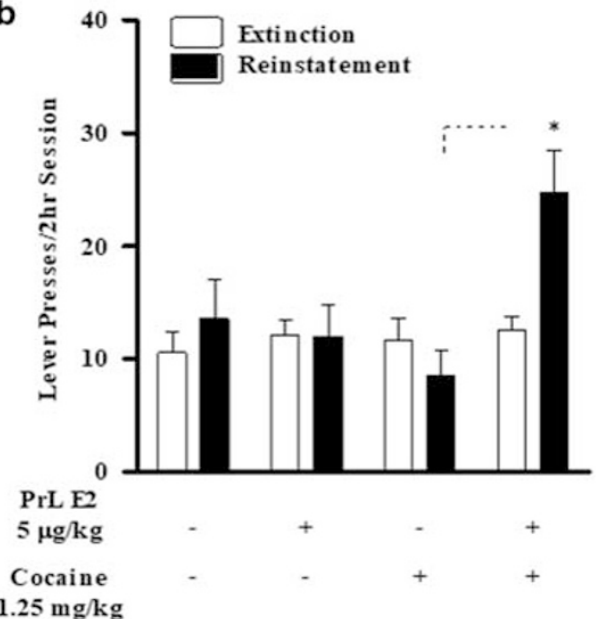

C

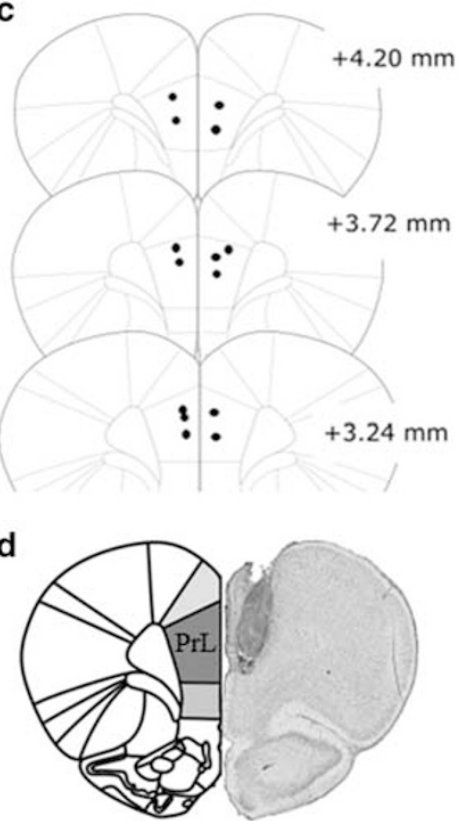

Figure 3 Intra-PrL E2 potentiates the reinstatement of cocaine seeking to subthreshold cocaine priming dose. Following re-establishment of extinction criterion post-ovariectomy, females were tested for reinstatement in response to intra-PrL E2 and $1.25 \mathrm{mg} / \mathrm{kg}$ cocaine. (a) Timeline for intra-PrL E2potentiated reinstatement. (b) Testing for the effects of intra-PrL $5 \mu \mathrm{g} / 0.3 \mu \mathrm{l}$ E2 on reinstatement in response to I.25 mg/kg OVXed females. (c) PrL cannulae placements for intra-PrL E2 microinfusions. (d) Representative histology image of PrL cannulae placements. Data are represented as mean \pm SEM. * $P<0.05$.

ANOVA revealed a significant interaction between day and treatment $\left(\mathrm{F}_{(3,12)}=5.630, p<0.05\right)$. The $\mathrm{E} 2$ effects on reinstatement were dose-dependent, as post hoc tests revealed significant responding during reinstatement relative to extinction following $100 \mu \mathrm{g} / \mathrm{kg} \mathrm{E} 2 /$ cocaine $(p<0.05)$.

\section{Experiment 2: Intra-PrL E2-Potentiated Reinstatement of Cocaine Seeking in OVXed Females}

To investigate the PrL-PFC contribution to E2-potentiated reinstatement, we determined the ability of bilateral intraPrL E2 injections $(5 \mu \mathrm{g} / 0.3 \mu \mathrm{l} /$ side; 15 -min pretreatment) to potentiate cocaine seeking in response to $1.25 \mathrm{mg} / \mathrm{kg}$ cocaine ( $n=7$; see Figure 3 a for design). As with systemic E2, neither intra-PrL E2 nor $1.25 \mathrm{mg} / \mathrm{kg}$ cocaine alone reinstated cocaine seeking, but robust reinstatement was observed with their combination (Figure 3b). A two-way repeated-measures ANOVA showed a main effect of day (extinction $v s$ reinstatement, $\left.\mathrm{F}_{(1,6)}=7.970, p<0.05\right)$, treatment $\left(\mathrm{F}_{(3,18)}=\right.$ $3.317, p<0.05)$, and a significant interaction $\left(\mathrm{F}_{(3,18)}=4.633\right.$, $p<0.05)$. Post hoc tests revealed significant responding during reinstatement relative to extinction in the intra-PrL PFC E2/cocaine condition $(p<0.05)$. Intra-PrL E2/vehicle cannulae placements are depicted in Figure $3 c$, and a representative PrL histology image is shown in Figure $3 \mathrm{~d}$.

\section{Experiment 3: Role of CB1R Activation in E2- Potentiated Reinstatement}

We previously reported a role for endocannabinoid signaling via CB1Rs in corticosterone-potentiated cocaine-primed reinstatement in male rats (McReynolds et al, 2016). To determine whether $\mathrm{CB} 1 \mathrm{R}$ activation has a similar role in E2-potentiated reinstatement, female rats were tested for
E2-potentiated reinstatement following pretreatment with the CB1R inverse agonist, AM251 (see Figure 4a for design). AM251 pretreatment ( 1 or $3 \mathrm{mg} / \mathrm{kg}$, i.p.; 30 -min pretreatment) prior to $\mathrm{E} 2(10 \mu \mathrm{g} / \mathrm{kg}, 1-\mathrm{h}$ pretreatment) and cocaine $(1.25 \mathrm{mg} / \mathrm{kg})$ dose-dependently reduced potentiated reinstatement ( $n=7$; Figure $4 \mathrm{~b}$ ). A two-way repeated-measures ANOVA showed significant main effects of day (extinction vs reinstatement; $\left.\mathrm{F}_{(1,6)}=9.373, \quad p<0.05\right)$, treatment $\left(\mathrm{F}_{(5,30)}=3.000, \quad p<0.05\right)$, and a significant interaction $\left(F_{(5,30)}=3.948, p<0.01\right)$. Post hoc testing revealed significant responding during reinstatement relative to extinction only in the vehicle/E2/cocaine condition $(p<0.05)$. Comparison across reinstatement test conditions using one-way repeatedmeasures ANOVA followed by post hoc testing revealed greater reinstatement in the vehicle/E2/cocaine condition relative to $3 \mathrm{mg} / \mathrm{kg}$ AM251/E2/cocaine $(p<0.05)$.

To determine whether CB1R activation is necessary specifically for E2 effects, or for cocaine-primed reinstatement generally, rats $(n=4)$ received systemic AM251 (1 or $3 \mathrm{mg} / \mathrm{kg}$, i.p.) or vehicle prior to testing for reinstatement in response to suprathreshold cocaine $(5 \mathrm{mg} / \mathrm{kg}$, i.p.; see Figure 4c for design). AM251 pretreatment did not suppress reinstatement to suprathreshold cocaine (Figure $4 \mathrm{~d}$ ). Twoway ANOVA showed main effects of day (extinction $v s$ reinstatement; $F_{(1,3)}=39.256, p<0.01$ ), but no effects of treatment or interactions. Post hoc tests did not reveal significant differences in reinstatement responding between conditions.

To determine whether PrL-PFC CB1R activation is necessary for E2-potentiated reinstatement, rats $(n=7)$ received bilateral PrL-PFC AM251 $(0.3 \mu \mathrm{g} / 0.3 \mu \mathrm{l} /$ side; $15-$ min pretreatment) or vehicle injections prior to testing for reinstatement in response to $\mathrm{E} 2(10 \mu \mathrm{g} / \mathrm{kg} ; 1-\mathrm{h}$ pretreatment) and low-dose cocaine (1.25 mg/kg; see Figure $4 \mathrm{e}$ for design). 
a

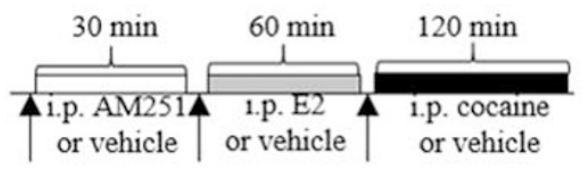

b

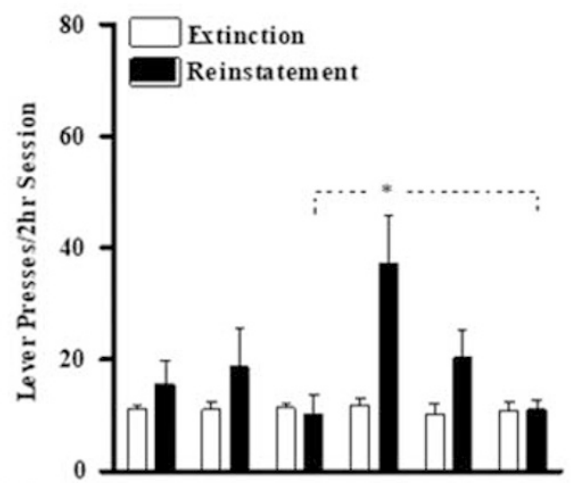

E2

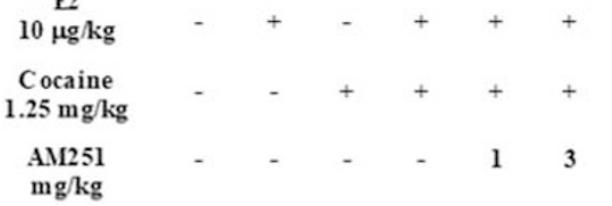

C

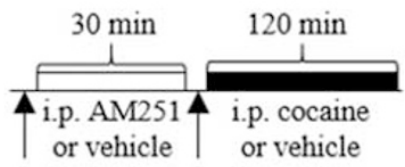

d

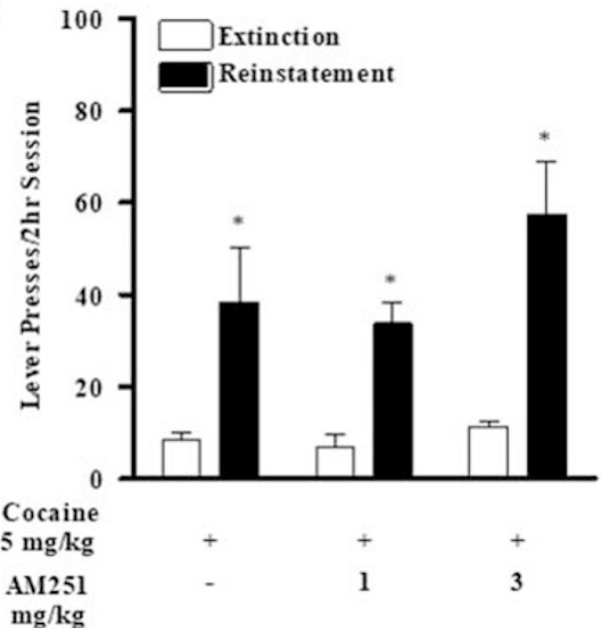

e

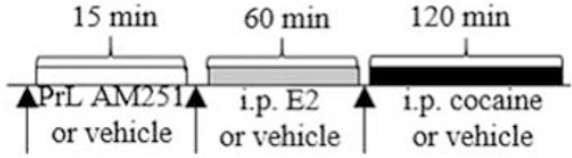

f

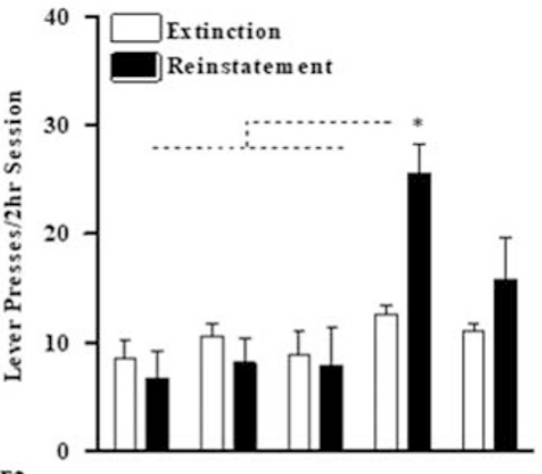

E2

$10 \mu \mathrm{g} / \mathrm{kg}$

Cocaine

$1.25 \mathrm{mg} / \mathrm{kg}$

Intra-PrL AM251

$0.3 \mu \mathrm{g} / 0.3 \mu \mathrm{L}$

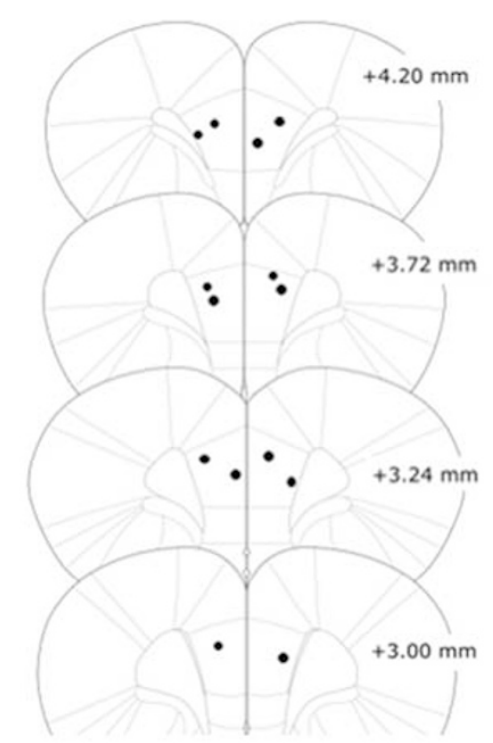

h

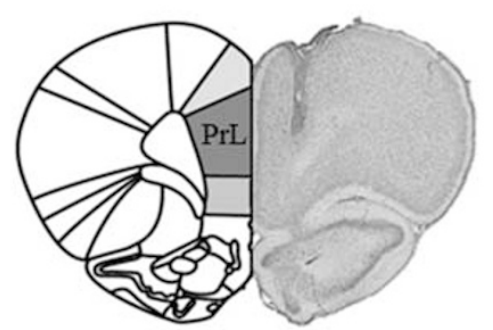

Figure 4 Necessity for CBIR activation in E2-potentiated reinstatement of cocaine seeking in OVXed females. (a) Timeline for CBIR antagonism in E2-

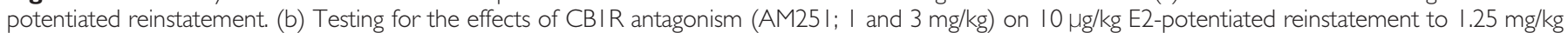
cocaine in OVXed females. (c) Timeline for CBIR necessity in cocaine-primed reinstatement. (d) Testing for the requirement of CBIR activation (AM25 I; I and $3 \mathrm{mg} / \mathrm{kg}$ ) in $5 \mathrm{mg} / \mathrm{kg}$ cocaine-primed reinstatement in OVXed females. (e) Timeline for intra-PrL CBI antagonism in E2-potentiated reinstatement. (f) Testing for E2-potentiated reinstatement following intra-PrL CBI (AM25I; 300 ng/0.3 Hl) antagonism. (g) PrL cannulae placements for intra-PrL CBI antagonist microinfusions. (h) Representative histology image of PrL cannulae placements. Data are represented as mean $\pm S E M$. $* P<0.05$. 
Intra-PrL AM251 significantly attenuated, but did not fully block, E2-potentiated reinstatement (Figure 4f). A two-way repeated-measures ANOVA revealed a trend towards a main effect of day (extinction $v s$ reinstatement; $\mathrm{F}_{(1,6)}=4.450$, $p=0.079)$, a significant main effect of treatment $\left(\mathrm{F}_{(4,24)}=6.449, \quad p<0.001\right)$, and an interaction between reinstatement and treatment $\left(\mathrm{F}_{(4,24)}=3.609, p<0.05\right)$. Post hoc testing revealed significant responding during reinstatement relative to extinction under the intra-PrL PFC vehicle/ E2/cocaine condition $(p<0.01)$. Comparison across reinstatement test conditions using one-way repeated-measures ANOVA followed by post hoc testing revealed greater reinstatement in the vehicle/E2/cocaine condition relative to vehicle/HBC/saline $(p<0.001), \quad$ vehicle/E2/saline $(p=0.05)$, and vehicle/HBC/cocaine $(p<0.05)$. However, no statistically significant differences were observed between the AM251/E2/cocaine condition and the other reinstatement conditions. Intra-PrL AM251/vehicle cannulae placements are depicted in Figure $4 \mathrm{~g}$, and a representative PrL histology image is shown in Figure $4 \mathrm{f}$.

\section{DISCUSSION}

We demonstrated that acute proestrus-level E2 potentiates cocaine seeking in OVXed female rats, in part via PrL-PFC CB1R-dependent actions. We found that E2 $(10 \mu \mathrm{g} / \mathrm{kg}$, i.p.) alone is insufficient to reinstate cocaine seeking but does potentiate reinstatement in response to ordinarily subthreshold cocaine $(1.25 \mathrm{mg} / \mathrm{kg}$, i.p.). These findings align with prior reports of greater propensity to drug seeking during heightened estrogen phases (Kippin et al, 2005; Feltenstein et al, 2011; Feltenstein and See, 2007) and are consistent with our own observation of reinstatement to subthreshold cocaine only during proestrus. Moreover, they extend a report that 9 days of $\mathrm{E} 2$ administration promotes cocaineprimed reinstatement in OVXed female rats (Larson et al, 2005) by demonstrating that acute E2 is sufficient to promote cocaine seeking. The observation that peak physiological E2 levels can 'set the stage' for drug seeking in females is akin to our prior findings that stress-response level corticosterone also potentiates cocaine-primed reinstatement in males (Graf et al, 2013; McReynolds et al, 2016).

\section{PrL-PFC E2 Actions}

The E2 influence on cocaine seeking likely involves the PrLPFC. Intra-PrL E2 injections reproduced the potentiating effects of proestrus-level E2 on cocaine seeking. As activation of PrL-PFC glutamatergic projections to the nucleus accumbens is critical for cocaine-primed reinstatement (Capriles et al, 2003; McFarland et al, 2003; Kalivas and Volkow, 2005; Stefanik et al, 2013), we hypothesize that E2 acts within the PrL-PFC to facilitate activation of this pathway, likely by enhancing pyramidal neuron excitability. Accordingly, E2 both enhances excitation (Oberlander and Woolley, 2016) and suppresses inhibition (Huang and Woolley, 2012; Tabatadze et al, 2015) of pyramidal neurons in other brain regions. Furthermore, basal PFC dopamine levels fluctuate in an estrous cycle-dependent manner (Dazzi et al, 2007). Finally, heightened PFC c-fos activity corresponds to elevated E2 levels (Wang et al, 2004) and augmented cocaine seeking in females (Zhou et al, 2014). Thus we hypothesize that low-dose cocaine produces an excitatory drive on accumbens-projecting PrL pyramidal neurons that is subthreshold for pathway activation, except within an elevated E2 context.

It is unclear whether findings derived using a cocaineprimed reinstatement procedure can extend to other reinstatement triggers. Although the PrL-PFC appears generally important for drug-seeking behavior (Kalivas and Volkow, 2005), the neural circuitry underlying cocaineprimed reinstatement may differ from context-, cue-, and stress-induced reinstatement (e.g., Lasseter et al, 2010). Future studies will investigate the ability of E2 to potentiate reactivity to other triggers.

\section{Endocannabinoid Signaling: Estrogen Regulation}

E2 could modulate PrL-PFC neuronal excitability through endocannabinoid signaling regulation. Estrogens have been reported to mobilize endocannabinoids (El-Talatini et al, 2010; Huang and Woolley, 2012; Tabatadze et al, 2015; Peterson et al, 2016) and regulate CB1R binding (Rodriguez de Fonseca et al, 1994; Castelli et al, 2014; Riebe et al, 2010). PrL-PFC CB1Rs in females are expressed on the same interneuron terminals that exert tonic inhibitory constraint on pyramidal neurons in males (Chiu et al, 2010; Hill et al, 2011), and in males, PrL-PFC CB1R activation suppresses this GABAergic inhibition (Hill et al, 2011). In the present study, systemic CB1R antagonism (AM251; 1 or $3 \mathrm{mg} / \mathrm{kg}$, i.p.) suppressed E2-potentiated reinstatement in a dosedependent manner, demonstrating that E2 effects on cocaine seeking are attributable to endocannabinoid mobilization and CB1R activation. By contrast, the same AM251 doses failed to block reinstatement to suprathreshold cocaine (5 mg/kg, i.p.), consistent with our previous findings in males (McReynolds et al, 2016), indicating that, while CB1R activation mediates the E2 influence on cocaine seeking, it is not required for cocaine-primed reinstatement in the absence of elevated E2 levels. The PrL-PFC endocannabinoid signaling contribution to E2-potentiated cocaine seeking was tested by administering PrL-PFC AM251 prior to E2 and cocaine, which suppressed E2-potentiated reinstatement. E2induced CB1R-mediated suppression of inhibition may, therefore, render the PrL-PFC more excitable by ordinarily subthreshold triggers and thus enhance relapse vulnerability.

\section{E2-Potentiated Reinstatement: Alternative Mechanisms}

Although PrL-PFC CB1R antagonism attenuated E2potentiated cocaine seeking, in contrast to systemic AM251, intra-PrL-PFC AM251 failed to fully block potentiated reinstatement. There are several reasons why this may have occurred. First, we were unable to test AM251 concentrations $>0.3 \mu \mathrm{g} /$ side due to solubility issues, as the greater DMSO concentrations required to solubilize AM251 suppressed reinstatement under vehicle control conditions (data not reported). Thus it is possible that we were unable to achieve complete PrL-PFC CB1R antagonism. Second, the ability of E2 to produce widespread effects throughout the brain suggests that E2-CB1R effects in multiple brain regions, such as the nucleus accumbens and ventral tegmental area, may converge to enhance cocaine seeking 
during heightened estrogen periods. For example, E2 has been reported to produce CB1R-dependent effects on nucleus accumbens spine density, which correspond to cocaine sensitization (Peterson et al, 2016). Third, E2 regulation of the HPA axis could contribute to its effects on cocaine seeking. $17 \beta$-Estradiol stimulates corticosterone release (Lo et al, 2000; Niyomchai et al, 2005; Weiser and Handa, 2009), and corticosterone attenuates PrL-PFC inhibitory synaptic transmission via endocannabinoid mobilization and CB1R activation (Hill et al, 2011) and potentiates reinstatement in a CB1R-dependent manner in males (McReynolds et al, 2016). However, as intra-PrL E2 recapitulates the systemic E2 effects on cocaine seeking, it is unlikely that E2-induced HPA axis activation exclusively accounts for its effects on reinstatement.

Although the receptor mechanism through which PrLPFC E2 acts to promote cocaine seeking is unclear, the rapid effects suggest a non-genomic mechanism of action. Estrogen receptor- $\alpha(\mathrm{ER} \alpha)$, estrogen receptor- $\beta(\mathrm{ER} \beta)$, and G-protein-coupled estrogen receptor-1 (GPER1) are all expressed in the PFC and, although primarily localized to presynaptic axon terminals, they are also found in dendrites where they could regulate endocannabinoid production (Almey et al, 2014). In the hippocampus, E2 activation of $\mathrm{ER} \alpha$ mobilizes the endocannabinoid, $N$-arachidonoylethanolamine, via interaction with mGluR1, resulting in a CB1Rdependent attenuation of GABA release in females (Huang and Woolley, 2012; Tabatadze et al, 2015). The CB1Rdependent ability of E2 to promote behavioral sensitization also requires an $\mathrm{ER} \alpha-\mathrm{mGluR} 1$ interaction (Peterson et al, 2016). However, it is unknown whether similar regulation occurs in the PFC. $\mathrm{ER} \beta$ increases presynaptic glutamate transmission in the female rat hippocampus (Oberlander and Woolley, 2016) and is required for potentiation of excitatory synaptic transmission in the female mouse hippocampus (Galvin and Ninan, 2014). Moreover, chronic ER $\beta$, but not $\mathrm{ER} \alpha$, activation promotes cocaine-primed reinstatement in female rats (Larson and Carroll, 2007). However, it is unclear how $\operatorname{ER} \beta$-induced endocannabinoid signaling could increase excitatory synaptic function. Although GPER1 activation increases postsynaptic glutamate sensitivity (Oberlander and Woolley, 2016), effects on endocannabinoid signaling have not been reported.

\section{OVX and Physiological E2 Considerations}

One caveat of the present study was that rats were surgically ovariectomized to permit precise control over E2 levels during reinstatement testing. Importantly, to avoid effects on cocaine self-administration (Zhao and Becker, 2010; Lynch and Taylor, 2005) and extinction (Twining et al, 2013) that could later confound reinstatement, rats underwent OVX after selfadministration and extinction and just before reinstatement testing. The purpose of the experiment was to reproduce proestrus-level E2 and assess effects on cocaine seeking. However, we did not directly compare the effects of the proestrus E2 dose with lower E2 doses that recapitulate other estrous cycle phases. We did, however, demonstrate that potentiated reinstatement is only observed in response to $1.25 \mathrm{mg} / \mathrm{kg}$ cocaine during proestrus in gonadally intact females and that the E2 effects on cocaine seeking are dose-dependent, as supraphysiological E2 levels further augmented reinstatement vulnerability. Additionally, chronic OVX has been shown to attenuate cocaine-primed reinstatement (Larson et al, 2005; Larson and Carroll, 2007), so elevating E2 in the face of chronically depleted estrogens likely has differential consequences for cocaine seeking than what is observed in intact cycling rats in proestrus. Indeed, OVX produces neuroadaptations that could modulate behavior, including $\mathrm{CB} 1 \mathrm{R}$ and ER binding and expression changes in brain regions associated with cocaine seeking (Rodriguez de Fonseca et al, 1994; Riebe et al, 2010; Castelli et al, 2014; Rose'Meyer et al, 2003; Bastos et al, 2015). Moreover, we report higher proestrus E2 levels in cocaine-naive females than those reported following self-administration (Feltenstein and See, 2007), suggesting that a dose recapitulating cocaine-naive proestrus E2 levels could prove supraphysiological in cocaineexperienced OVX females. However, whether E2 levels are persistently suppressed following self-administration is unknown.

\section{Progesterone Influence Over Relapse}

Although the present findings implicate E2 as a key determinant of sex and cycle-related influences on cocaine use, other sex hormones are also likely involved. Most notably, while estrogens may act to enhance relapse vulnerability, progesterone may provide protection against it (Sofuoglu et al, 2002; Evans and Foltin, 2006; Sinha et al, 2007). Higher reinstatement responding is observed during low progesterone phases (Feltenstein and See, 2007). Future experiments will examine how covariation in E2 and progesterone levels relate to reinstatement vulnerability.

\section{CONCLUSIONS}

Taken together, our findings provide evidence that high estrogen brain states can promote cocaine seeking through endocannabinoid signaling regulation and PrL-PFC actions. These findings have implications for understanding sex differences in relapse vulnerability and variation in propensity to seek cocaine across the reproductive cycle in women. Moreover, as recent clinical findings suggest that, compared with men, women diagnosed with substance use disorder exhibit different sensitivity and responsiveness to some medications (Fox et al, 2013, 2014), the ability of E2 to regulate endocannabinoid signaling in females may guide the development of sex-specific treatment approaches aimed at relapse prevention.

\section{FUNDING AND DISCLOSURE}

These studies were supported by DA15758 and DA038663 from the National Institute on Drug Abuse. The authors declare no conflicts of interest.

\section{ACKNOWLEDGMENTS}

We thank Dr Madalyn Hafenbreidel for advice concerning catheter surgeries; Dr Robert Twining for advice with statistical analyses; and Chaz Konrath, Erik Van Newenhizen, Devon Blob, and Luke Schuh for technical assistance. 


\section{REFERENCES}

Almey A, Cannell E, Bertram K, Filardo E, Milner TA, Brake WG et al (2014). Medial prefrontal cortical estradiol rapidly alters memory system bias in female rats: ultrastructural analysis reveals membrane-associated estrogen receptors as potential mediators. Endocrinology 155: 4422-4432.

Anker JJ, Carroll ME (2011). Females are more vulnerable to drug abuse than males: evidence from preclinical studies and the role of ovarian hormones. Curr Top Behav Neurosci 8: 73-96.

Bastos CP, Pereira LM, Ferreira-Vieira TH, Drumond LE, Massensini AR, Moraes MFD et al (2015). Object recognition memory deficit and depressive-like behavior caused by chronic ovariectomy can be transitorialy recovered by the acute activation of hippocampal estrogen receptors. Psychoneuroendocrinology 57: 14-25.

Capriles N, Rodaros D, Sorge RE, Stewart J (2003). A role for the prefrontal cortex in stress- and cocaine-induced reinstatement of cocaine seeking in rats. Psychopharmacology 168: 66-74.

Carpenter MJ, Upadhyaya HP, LaRowe SD, Saladin ME, Brady KT (2006). Menstrual cycle phase effects on nicotine withdrawal and cigarette craving: a review. Nicotine Tob Res 8: 627-638.

Castelli M, Fadda P, Casu A, Spano MS, Casti A, Fratta W et al (2014). Male and female rats differ in brain cannabinoid CB1 receptor density and function and in behavioural traits predisposing to drug addiction: effect of ovarian hormones. Curr Pharm Des 20: 2100-2113.

Chiu CQ, Puente N, Grandes P, Castillo PE (2010). Dopaminergic modulation of endocannabinoid-mediated plasticity at GABAergic synapses in the prefrontal cortex. $J$ Neurosci 30: 7236-7248.

Dazzi L, Seu E, Cherchi G, Barbieri PP, Matzeu A, Biggio G et al (2007). Estrous cycle-dependent changes in basal and ethanolinduced activity of cortical dopaminergic neurons in the rat. Neuropsychopharm 32: 892-901.

El-Talatini MR, Taylor AH, Konje JC (2010). The relationship between plasma levels of the endocannabinoid, anandamide, sex steroids, and gonadotrophins during the menstrual cycle. Fertil Steril 93: 1989-1996.

Epstein DH, Preston KL, Stewart J, Shaham Y (2006). Toward a model of drug relapse: an assessment of the validity of the reinstatement procedure. Psychopharmacology 189: 1-16.

Evans SM, Foltin RW (2006). Exogenous progesterone attenuates the subjective effects of smoked cocaine in women, but not in men. Neuropsychopharmacology 31: 659-674.

Feltenstein MW, Henderson AR, See RE (2011). Enhancement of cue-induced reinstatement of cocaine-seeking in rats by yohimbine: sex differences and the role of the estrous cycle. Psychopharmacology 216: 53-62.

Feltenstein MW, See RE (2007). Plasma progesterone levels and cocaine-seeking in freely cycling female rats across the estrous cycle. Drug Alcohol Depend 89: 183-189.

Fox HC, Morgan PT, Sinha R (2014). Sex differences in guanfacine effects on drug craving and stress arousal in cocaine-dependent individuals. Neuropsychopharmacology 39: 1527-1537.

Fox HC, Sofuoglu M, Morgan PT, Tuit KL, Sinha R (2013). The effects of exogenous progesterone on drug craving and stress arousal in cocaine dependence: impact of gender and cue type. Psychoneuroendocrinology 38: 1532-1544.

Gallop RJ, Crits-Christoph P, Ten Have TR, Barber JP, Frank A, Griffin ML et al (2007). Differential transitions between cocaine use and abstinence for men and women. J Consult Clin Psychol 75: 95-103.

Galvin C, Ninan I (2014). Regulation of the mouse medial prefrontal cortical synapses by endogenous estradiol. Neuropsychopharmacology 39: 2086-2094.

Graf EN, Wheeler RA, Baker DA, Ebben AL, Hill JE, McReynolds JR et al (2013). Corticosterone acts in the nucleus accumbens to enhance dopamine signaling and potentiate reinstatement to cocaine seeking. J Neurosci 33: 11800-11810.

Hill MN, McLaughlin RJ, Pan B, Fitzgerald ML, Roberts CJ, Lee TT et al (2011). Recruitment of prefrontal cortical endocannabinoid signaling by glucocorticoids contributes to termination of the stress response. J Neurosci 31: 10506-10515.

Huang GZ, Woolley CS (2012). Estradiol acutely suppresses inhibition in the hippocampus through a sex-specific endocannabinoid and mGluR-dependent mechanism. Neuron 74: 801-808.

Justice AJ, de Wit H (2000). Acute effects of estradiol pretreatment on the response to d-amphetamine in women. Neuroendocrinology 71: 51-59.

Kalivas PW, Volkow ND (2005). The neural basis of addiction: a pathology of motivation and choice. Am J Psychiatry 162: 1403-1413.

Kippin TE, Fuchs RA, Mehta RH, Case JM, Parker MP, BimonteNelson HA et al (2005). Potentiation of cocaine-primed reinstatement of drug seeking in female rats during estrus. Psychopharmacology 182: 245-252.

Larson EB, Carroll ME (2007). Estrogen receptor beta, but not alpha, mediates estrogen's effect on cocaine-induced reinstatement of extinguished cocaine-seeking behavior in ovariectomized female rats. Neuropsychopharmacology 32: 1334-1345.

Larson EB, Roth ME, Anker JJ, Carroll ME (2005). Effect of short$v s$ long-term estrogen on reinstatement of cocaine-seeking behavior in female rats. Pharmacol Biochem Behav 82: 98-108.

Lasseter HC, Xie X, Ramirez DR, Fuchs RA (2010). Prefrontal cortical regulation of drug seeking in animal models of drug relapse. Curr Top Behav Neurosci 3: 101-117.

Lo MJ, Chang LL, Wang PS (2000). Effects of estradiol on corticosterone secretion in ovariectomized rats. J Cell Biochem 77: 560-568.

Lynch WJ, Carroll ME (2000). Reinstatement of cocaine selfadministration in rats: sex differences. Psychopharmacology 148: 196-200.

Lynch WJ, Taylor JR (2005). Decreased motivation following cocaine self-administration under extended access conditions: effects of sex and ovarian hormones. Neuropsychopharmacology 30: 927-935.

Martin-Garcia E, Bourgoin L, Cathala A, Kasanetz F, Mondesir M, Gutierrez-Rodriguez A et al (2016). Differential control of cocaine self-administration by GABAergic and glutamatergic CB1 cannabinoid receptors. Neuropsychopharmacology 41: 2192-2205.

McFarland K, Lapish CC, Kalivas PW (2003). Prefrontal glutamate release into the core of the nucleus accumbens mediates cocaineinduced reinstatement of drug-seeking behavior. J Neurosci 23: 3531-3537.

McReynolds JR, Doncheck EM, Vranjkovic O, Ganzman GS, Baker DA, Hillard CJ et al (2016). CB1 receptor antagonism blocks stress-potentiated reinstatement of cocaine seeking in rats. Psychopharmacology 233: 99-109.

Niyomchai T, Russo SJ, Festa ED, Akhavan A, Jenab S, QuinonesJenab V et al (2005). Progesterone inhibits behavioral responses and estrogen increases corticosterone levels after acute cocaine administration. Pharmacol Biochem Behav 80: 603-610.

Oberlander JG, Woolley CS (2016). 17ß-Estradiol acutely potentiates glutamatergic synaptic transmission in the hippocampus through distinct mechanisms in males and females. J Neurosci 36: 2677-2690.

Ong KC, Cheong GN, Prabhakaran L, Earnest A (2005). Predictors of success in smoking cessation among hospitalized patients. Respirology 10: 63-69.

Park WK, Bari AA, Jey AR, Anderson SM, Spealman SD, Rowlett JK et al (2002). Cocaine administrated into the medial prefrontal cortex reinstates cocaine-seeking behavior by increasing AMPA receptor-mediated glutamate transmission in the nucleus accumbens. J Neurosci 22: 2916-2925.

Peterson BM, Martinez LA, Meisel RL, Mermelstein PG (2016). Estradiol impacts the endocannabinoid system in female rats to 
influence behavioral and structural responses to cocaine. Neuropharmacology 110: 118-124.

Reimers L, Buchel C, Diekhof EK (2014). How to be patient. The ability to wait for a reward depends on menstrual cycle phase and feedback-related activity. Front Neurosci 8: 401.

Riebe CJ, Hill MN, Lee TT, Hillard CJ, Gorzalka BB (2010). Estrogenic regulation of limbic cannabinoid receptor binding. Psychoneuroendocrinology 35: 1265-1269.

Rodriguez de Fonseca F, Cebeira M, Ramos JA, Martin M, Fernandez-Ruiz JJ (1994). Cannabinoid receptors in rat brain areas: sexual differences, fluctuations during estrous cycle and changes after gonadectomy and sex steroid replacement. Life Sci 54: 159-170.

Rose'Meyer RB, Mellick AS, Garnham BG, Harrison GJ, Massa HM, Griffiths LR et al (2003). The measurement of adenosine and estrogen receptor expression in rat brains following ovariectomy using quantitative PCR analysis. Brain Res Brain Res Protoc 11: 9-18.

Sinha R, Fox H, Hong KI, Sofuoglu M, Morgan PT, Bergquist KT et al (2007). Sex steroid hormones, stress response, and drug craving in cocaine-dependent women: implications for relapse susceptibility. Exp Clin Psychopharmacol 15: 445-452.

Sofuoglu M, Babb DA, Hatsukami DK (2002). Effects of progesterone treatment on smoked cocaine response in women. Pharmacol Biochem Behav 72: 431-435.
Stefanik MT, Moussawi K, Kupchik YM, Smith KC, Miller RL, Huff ML et al (2013). Optogenetic inhibition of cocaine seeking in rats. Addict Biol 18: 50-53.

Tabatadze N, Huang G, May RM, Jain A, Woolley CS (2015). Sex differences in molecular signaling at inhibitory synapses in the hippocampus. J Neurosci 35: 11252-11265.

Terner JM, de Wit H (2006). Menstrual cycle phase and responses to drugs of abuse in humans. Drug Alcohol Depend 84: 1-13.

Twining RC, Tuscher JJ, Doncheck EM, Frick KM, Mueller D (2013). 17 $\beta$-Estradiol is necessary for extinction of cocaine seeking in female rats. Learn Mem 20: 300-306.

Wang J, Cheng CM, Zhou J, Smith A, Weickert CS, Perman WR et al (2004). Estradiol alters transcription factor gene expression in primate prefrontal cortex. J Neurosci Res 76: 306-314.

Weiser MJ, Handa RJ (2009). Estrogen impairs glucocorticoid dependent negative feedback on the hypothalamic-pituitaryadrenal axis via estrogen receptor alpha within the hypothalamus. Neuroscience 159: 883-895.

Zhao W, Becker JB (2010). Sensitization enhances acquisition of cocaine self-administration in female rats: estradiol further enhances cocaine intake after acquisition. Horm Behav 58: 8-12.

Zhou L, Pruitt C, Shin CB, Garcia AD, Zavala AR, See RE et al (2014). Fos expression induced by cocaine-conditioned cues in male and female rats. Brain Struct Funct 219: 1831-1840.

Supplementary Information accompanies the paper on the Neuropsychopharmacology website (http://www.nature.com/npp) 